\title{
INCISIONAL HERNIA AFTER APPENDECTOMY: A CASE REPORT
}

\section{Sakher Maayeh MD*, Sadeq Da'meh MD**, Diana Alamro RN***Asma Thalji Alhuniti RN***, Pharm. Abdelkhaleg Shboul, Sokinah Ammro RN*** \\ *General surgery, (KHMC); **Anesthesia and intensive care, (KHMC); ***Nursing department, (Queen Aliaa Hospital)}

\section{ABSTRACT \\ Appendectomy is one of the most frequent of all surgical interventions. Thought it is technically considered as minor, its complication varies from infected wound, intra-abdominal abscess, paralytic ileus and incisional hernia. \\ Our case presents the complication of post-appendectomy incisional hernia containing small bowel segment.}

Key Words: incisional hernia, appendectomy.

\section{INTRODUCTION}

Tncisional hernia after open or laparoscopic surgery is defined as an abdominal wall defect with or without a bulge visible and palpable when the patient is standing during clinical examination, and often requiring support or repair ${ }^{1}$.

Few reports have dealt with incisional hernia originating at the site of appendectomy, and the incidence between $(0.4-0.7 \%){ }^{2}$

The risk factors for development of incisional hernia post appendectomy are:-

1- Female gender, obesity, smoking and advanced age.

2- Diabetes.

3- Peritonitis, abscess or phlegmon as the cause of the first operation.

4- Wound infection or seroma. ${ }^{3}$

5- Techniqual issues as the use of catgut to suture the aponeurosis or using interrupted suture for aponeuroitc layer. ${ }^{4}$

\section{Case Report}

A 47 year old female patient, single, with history of appendectomy 4 year ago complicated by wound infection. Referred from gynecologist as a case of acute abdomen and she was admitted as suspicion of torsion of ovarian cyst.
She noted in the history she had attack of abdominal pain and constipation 1 year after appendectomy without seeking any medical attention.

On examination, there was a distended abdomen with tender bulge above appendectomy scar, per rectum examination showed empty rectum and all vital signs were within normal.

Laboratory tests were within normal range.

Ultra sound showed herniated bowel within a defect at the site of previous surgery, $4 * 4 \mathrm{~cm}$ Right sided ovarian cyst with soft tissue echogenicity

CT- scan with intravenous contrast detected small bowel segment herniated in the abdominal wall defect, and dilated small bowel loops within the abdomen, and minimal free fluid in the pelvis was noted.

She was resuscitated with intravenous fluids and antibiotic, and laparotomy was performed and revealed $25 \mathrm{~cm}$ of terminal ileum herniated in an incisional hernia at the site of appendectomy with normal color and viable bowel (as illustrated in figure 1), and multiple adhesions and bands were noted around caecum and at site of previous surgery (as illustrated in figures 2).

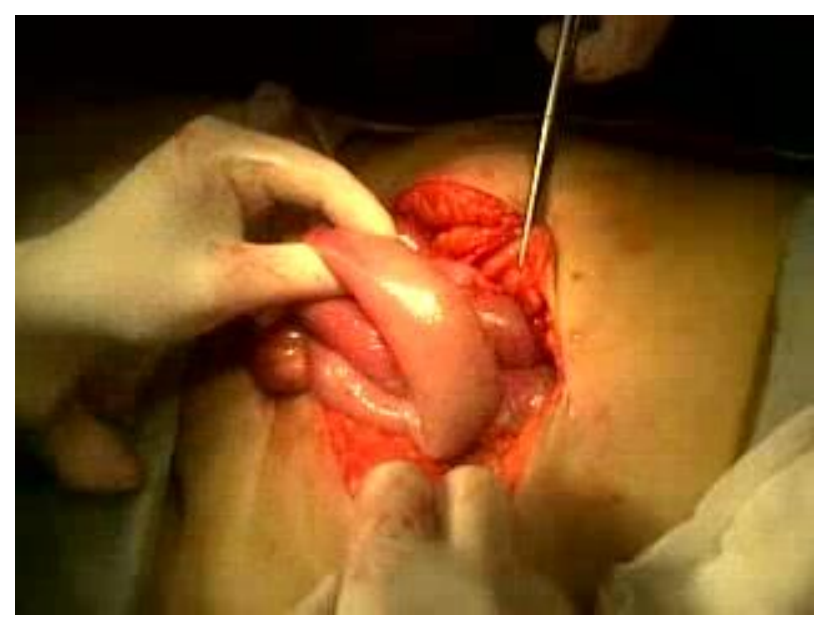


Figure 1

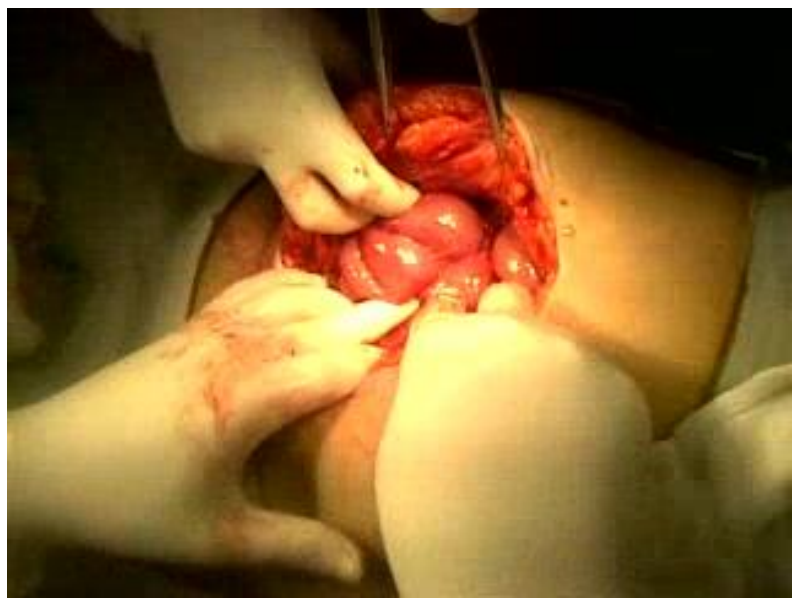

Figure 2

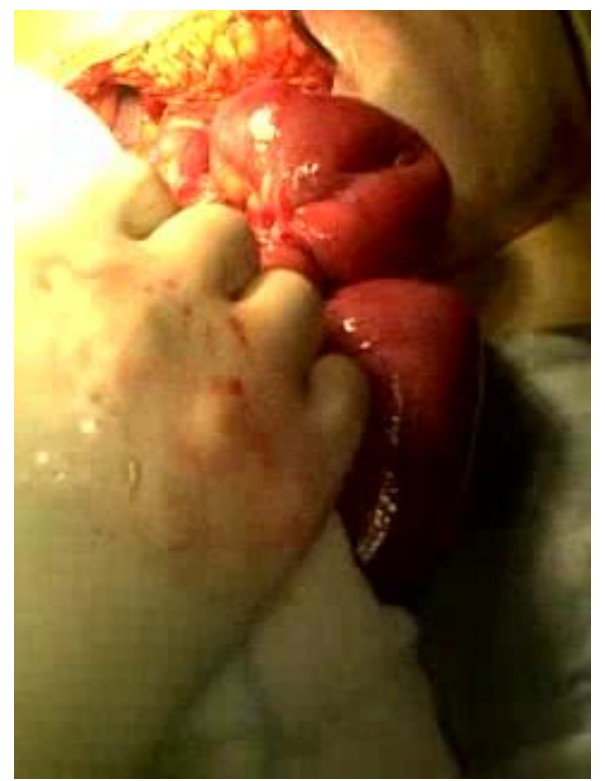

Figure 3

Adhesionlysis were done smoothly and milking the whole bowel toward the abdomen, and right ovarian cystectomy were done by gynecologist then the defect was repaired and reinforcement of the external aponeurosis was done.

The post operative course were uneventful, and without complications. Five days later the patient was discharged in a good condition.

\section{DISCUSSION}

Incisional hernia is defined as a palpable defect greater than $1 \mathrm{~cm}$. in close proximity to the scar through which a bulge is either palpable or visible when the patient is told to cough or on raising the legs in the examination position.
Incisional hernia after appendectomy considered as a late complication of the surgery ${ }^{5}$, and it may occur within first weeks to years ${ }^{6}$.

And the percentage of this complication less than $1 \%$ (between $0.4-0.7 \%$ ), and mostly all the patients had suffered a wound infection secondary to a perforated appendicitis ${ }^{7}$.

Although infection of the wound is without doubt the principal factor of incisional hernia post appendectomy, there are multiple primary causes that can favor its occurrence. Among those that in greatest measures contribute to the persistence of complications are factors inherent to the patient such as obesity, age and, above all, the existence of peritonitis before the intervention ${ }^{8}$. 
Also technical issues may play role in the occurrence of incisional hernia as careless suturing, the use of rapidly absorbable instead of nonabsorbable material, use of catgut to suture the aponeurosis or using interrupted suture for aponeuroitc layer'.

Primary repair of this form of hernia is particularly difficult as a result of the attenuated fascia created by the herniation, by using a synthetic mesh; it is possible to effectively repair this type of hernia ${ }^{10}$.

\section{CONCLUSION}

Incisional hernia one of the late complication of the appendectomy, we should deal with the risk factors to decrease the incidence of its occurrence, and if it occurs we prefer prosthetic repair.

\section{REFERENCES}

1- World journal of surgery (2008), Hernia , MA Beltrán, KS Cruces - World journal of surgery, 2008 - Springer, page(596-597).

2- Hernia, Springer-Verlag, AM Duce, O Lozano, R Villeta, JM Mugüerza, J Martín, 1998, page(169-170).
3- Shwartz's principles of surgery, F.Charles Brunicadi, Robert j. Fitzgibbons, jr. filipi,and Thomas h. Quinn, page(1355-1356).

4- General surgical operations, R. M. KIRK, Fifth Edition, D.F.L. Watkin, G.S.M Robertson, page (91-92).

5- Review of Surgery, Rush university medical center, Norman wool, Jose velasco, fifth edition, 2011, page (184-187).

6- Abdominal Wall Hernias, Principles and management, Robert Bendavid, Jack Abrahamson....2001, page (156-166).

7- Surgical Management Of Abdominal Wall Hernias, Martin Kurzer, Allen E Kark, George E Wantz...1999, page (227-240).

8- Essentials Of Abdominal Wall Hernias, Vinod Kumar, Siddharth Nigam...2008, page (215229).

9- Essentials Of General Surgery, Leigh Neumayer, Byron Mcgregor, Barry Mann....2006, page (225-236).

10- Complications In Surgery, Michael G. Franz, Gerard M. Doherty...2006, page(483-521). 